\title{
Network System on Physics Experiment for Teacher Application
}

\author{
Xiang TENG \\ Basic Teaching and Research Institute, Bohai University, Jinzhou, China
}

\begin{abstract}
With the further popularization of computer and network, networking and information is an important development direction of physics experiment teaching reform in colleges, so learning management for physics experiment can be achieved better if using the learning method of information. Firstly, the key technologies of the system was introduced; secondly, database design of the system was carried on, including requirement analysis, conceptual design, logical design, physical design, verification design, and operation and maintenance design; finally, elaborating the system's main function modules and the meaning of each module. The design of teacher application system of network management for physics experiment can greatly improve the learning quality, learning efficiency and experimental level of students and so on.
\end{abstract}

KEYWORD: Information; Physics experiment; Learning management; Application system

\section{INTRODUCTION}

College physics experiment is a required course for science and engineering majors, which has an important fundamental role for creating the abilities of innovation and practice and the overall quality, and its experimental methods are varied and comprehensive [1]. Traditional experiment teaching in colleges and universities general follows the model of "verification theory". So students do experiments only in accordance with the experiment procedure to "copy or imitate", which leads students are boring in the experiment class, let alone cultivating research ability. With the deepening of the reform of higher education, the expansion of teaching scale and the increase of the number of students, the teacher-student ratio is continuing to expand, the amount of data and traffic has increased exponentially, so the difficulty for experiment teachers to manage students has also increased. It is imperative to conduct information management for general physics experiments. With the development of network technology and the further advance of campus network, the development of teaching activities through network has been getting more and more attention in universities, and the campus network also provides the conditions for the research of this software project. The development of experimental network management system is a very good attempt [2].

\section{KEY TECHNOLOGY}

ADO.NET is a set of classes that provided by .NET Framework to .NET developers, its functions are comprehensive and flexible, so it can maintain the consistency of operations when developers access to a variety of different types of data. The design purpose of ADO.NET is to meet the requirements of the design model of new program, including: architecture of disconnected, tightly integrating XML, merging common data from multiple different databases, as well as optimizing the interaction with database, and these are basic functions possess by .NET Framework. These features of ADO.NET enable it to meet the development requirements of different forms and environments. ADO.NET provides two components: the data provider of .NET Framework and DataSet [3]. There are five major objects in ADO.NET for database to access and manipulate, they are Connection, Command, DataReader, DataAdapter, DataSet. Their operation database structure shows in Fig. 1.

(1) Connection object is responsible for connecting data sources.

(2) Command object can execute SQL commands or store procedures for data sources in order to obtain or modify data. In addition, it can send or retrieve parameter information.

(3) DataReader object provides sequence from the data source and high-performance data stream of read-only. 
(4) DataAdapter object is a bridge between DataSet object and data source. DataAdapter uses Command object to execute SQL statements or store procedures in the data source, so that the data will be loaded into the DataSet. Then it can also write the data change did by users in the DataSet back to the data source.

(5) DataSet object is responsible for accessing and updating data, its biggest advantages are offline and connection.

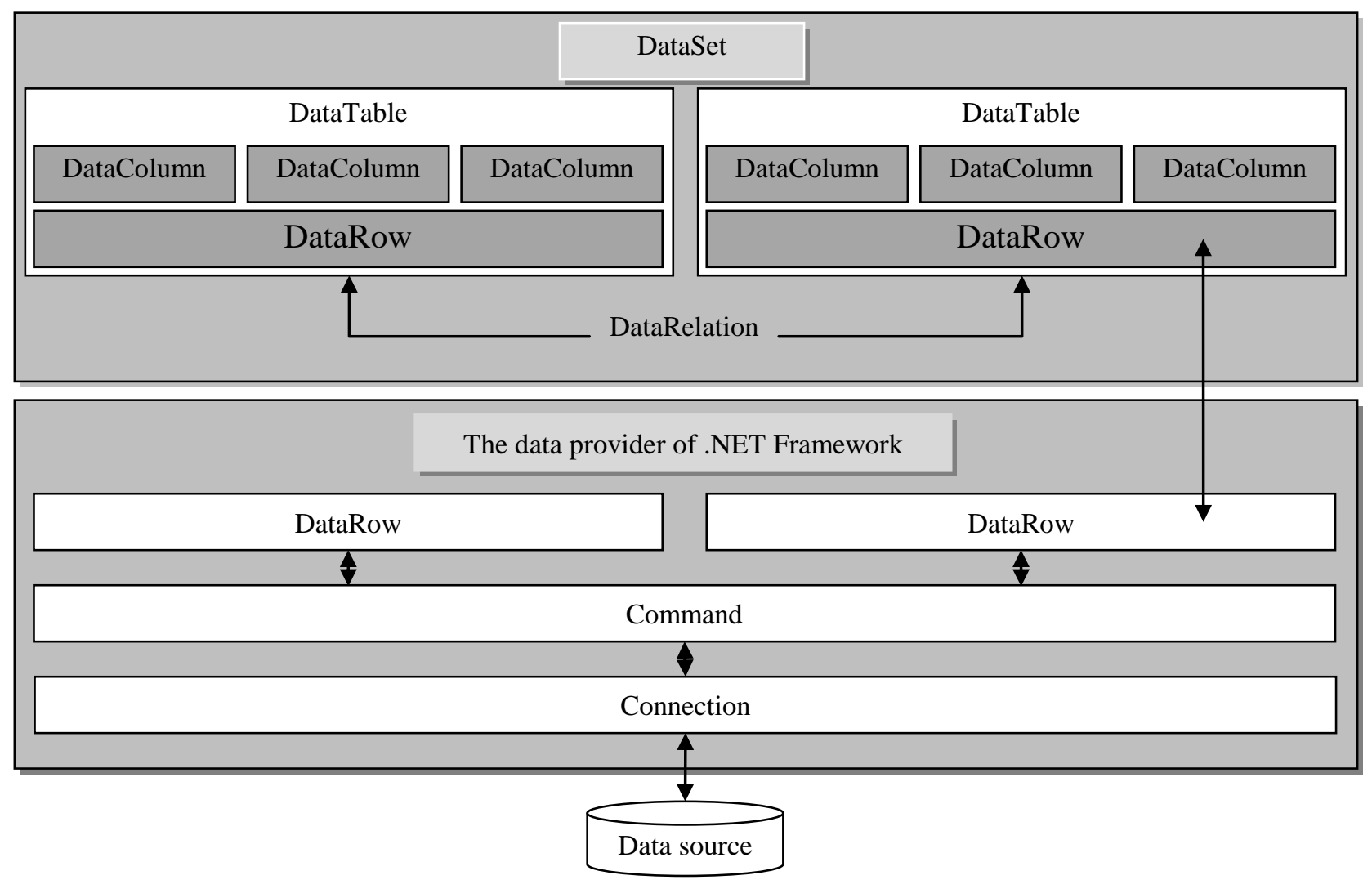

Fig. 1. The method of connecting database for ADO.NET

\section{DATABASE DESIGN}

Database design is a very important part for an application, which can directly affect the efficiency, stability and maintainability of the system [4]. Database design of high quality will reduce the amount of database storage, completeness and consistency of the data is high relatively, so the system has a fast response and it can simplify the implementation of database-based applications. The steps of database design can be divided into six steps: (1) requirement analysis: investigating and analysing business activities of users and use cases of data to determine the requirements and a variety of constraints of database system for users, so that the requirements specification of users will be formed; (2) conceptual design: the real world described by users can be abstracted to the conceptual data model. The model should use an abstract form to express rather than the specifics implemented on computer. Now commonly used model is the E-R model, which has become the main tool for conceptual structure design. E-R model is the model of entity and relationship, and there are two types of users in the system, namely teacher and student. Their relationship is many-to-many relationship, a teacher can manage a number of students; while a student can also be managed by a number of teachers; (3) logical design: conceptual data model got in the phase of conceptual design is designed to a logical model of the database, so the "logical database" will be got. The main data tables of system includes student table, teacher table, column table, document table and experimental issue table and others; (4) physical design: this phase is mainly responsible for selecting the most appropriate physical storage structure (including the file type, the index structure and the store order of data, etc.), storage method and storage path for specific application tasks to obtain so-called "physical database"; (5) verification design: on the basis of the above design, collecting data and establishing a database to run some typical application tasks to verify the correctness and rationality of its database design; (6) operation and maintenance design: in the process of operating database system, you must adjust and modify it constantly to ensure its robustness and integrity. 


\section{FUNCTION DESIGN}

The teacher application system mainly used by teachers, teacher management module is mainly responsible for centre introduction, issuing experiment notification, viewing student information, entering the experiment principle, assessing student achievement, viewing student achievement, online tutorial, and teaching resource. The specific design of the model shows in Fig. 2. The main functions of each module are described as follows.

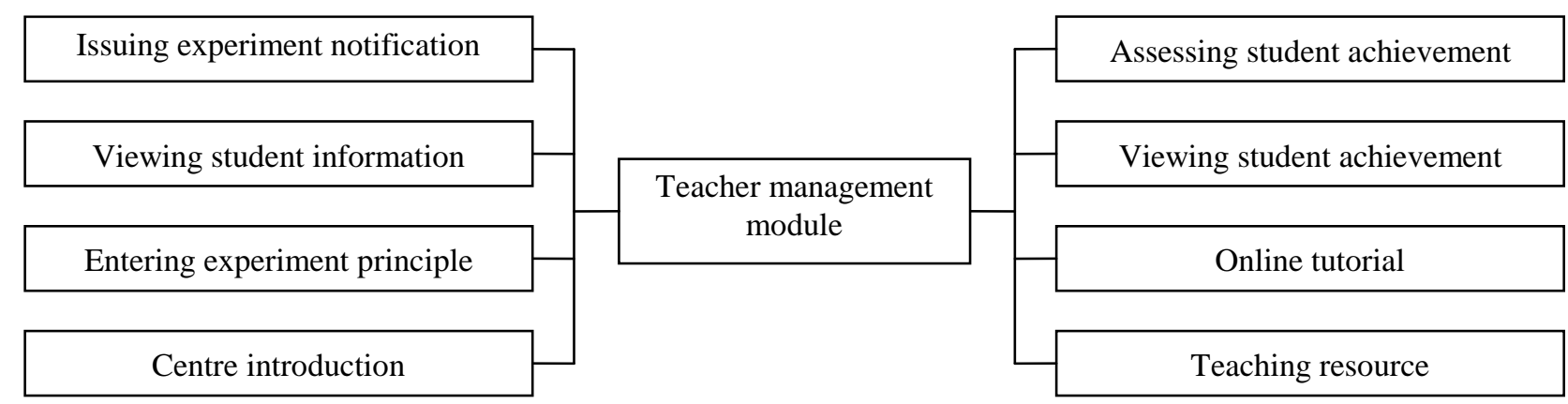

Fig. 2. The framework of network system

(1) Centre introduction: this module introduces the development, faculty, teaching tasks and major teaching and research achievements of physics experiment center and so on. After the teacher has released information, students can understand the basic overview of the experiment center through the module to do preliminary preparation for learning [5].

(2) Issuing experiment notification: this module is mainly responsible for issuing the experiment notifications to students, including experiment date and experiment subject, so students can know the experiment content in advance to prepare for the experiment, thus the efficiency of learning can be improved.

(3) Viewing student information: teachers can learn more about the students to help them learn by querying the basic information of students.

(4) Entering experiment principle: in this module, teachers must enter the experiment principle to help students remember and learn.

(5) Assessing student achievement: in this module, teachers need to assess students' academic achievement according to experiment reports submitted by them and their performance in the classroom.

(6) Viewing student achievement: this module can realize the function of querying all students' achievements. Achievement report shows in Fig. 3.

(7) Online tutorial: tutorial module can give a non-real-time interactive environment for teachers and students, and it can save the issues to provide reference for all. The questions rose in tutorial module and all responses are included in the tutorial knowledge base, so that the discussion contents of the teachers and students get effective storage management as valuable teaching experience data.

(8) Teaching resource: the module has a wealth of relevant experiment resources, and these resources can be free downloaded by students. These teaching resources published by the teachers.

\section{CONCLUSION}

Open experimental network management system replaced the traditional manual management mode completely with the features of information, networking and intelligentize, while it also has reference to the construction of other experiment teaching information. The system takes advanced and applicable software development model and process to lay the foundation for the later information process, which better complies with the requirements of universities [6]. The design of teacher application system of network management for physics experiment can provide a rich content, new structure, easy-to-use teaching window for the majority of teachers and students, and teachers can analyze students' information through the system to provide targeted guidance for learners. The system has great significance in improving the teaching quality, teaching efficiency and experimental level of students [7]. 


\section{Score Report on Physics Experiment}

Experiment name: Quality and density on measurement

Experiment name: $2014-09-20$

\begin{tabular}{|c|c|c|c|c|c:c|c|}
\hline $\begin{array}{c}\text { Student } \\
\text { D }\end{array}$ & $\begin{array}{c}\text { Student } \\
\text { Name }\end{array}$ & $\begin{array}{c}\text { Guidance } \\
\text { Teacher }\end{array}$ & Class & Group & $\begin{array}{c}\text { Operating } \\
\text { score }\end{array}$ & $\begin{array}{c}\text { Report } \\
\text { score }\end{array}$ & $\begin{array}{c}\text { Total } \\
\text { score }\end{array}$ \\
\hline 201404001 & Jackson & Stephanie & Class 20 & Group A & 92.50 & 86.00 & 89.25 \\
\hline 201404002 & Leopold & Stephanie & Class 20 & Group A & 69.00 & 77.00 & 73.00 \\
\hline 201404003 & Ultraman & Stephanie & Class 20 & Group A & 78.00 & 82.50 & 80.25 \\
\hline 201404004 & William & Stephanie & Class 20 & Group A & 85.00 & 90.50 & 87.75 \\
\hline 201404005 & Cinderella & Abraham & Class 20 & Group B & 94.00 & 76.00 & 85.00 \\
\hline 201404006 & Frances & Abraham & Class 20 & Group B & 73.50 & 64.50 & 69.00 \\
\hline 201404007 & Cassandra & Abraham & Class 20 & Group B & 87.50 & 73.00 & 80.25 \\
\hdashline 201404008 & Chelsea & Abraham & Class 20 & Group B & 82.00 & 81.00 & 81.50 \\
\hline 201404009 & Adalheid & Abraham & Class 20 & Group B & 74.00 & 92.50 & 83.25 \\
\hline
\end{tabular}

Fig. 3. Achievement report

\section{ACKNOWLEDGEMENT}

This work is supported by "Teaching Reform Project of Bohai University: Research and practice on modern physics virtual experiment simulation system of development.

\section{REFERENCES}

[1] H. Y. Chi, H. W. Ding, "Construction and Practice of Network Platform for Physics Experiment," China Electric Power Education, vol. 29, no. 16, pp. 155-156, 2013.

[2] L. F. He, "Research and Development of Network Teaching and Management System of Basic Physics Experiment," China Education Innovation Herald, vol. 36, no. 19, pp. 56-57, 2007.

[3] Y. Huang, X. F. He, X. Y. Zhou, "Design and Implementation of Online Examination Management
System Based on ADO.NET," Computer Knowledge and Technology, vol. 5, no. 36, pp. 10602-10603, 2009.

[4] H. Y. An, "Open Experiment Management System of University Based on .NET," Master's degree of East China Normal University, 2008.

[5] Y. B. Huang, H. Y. Du, J. Li, "Development and Realization of the Network Teaching Platform for College Physical Experiments," Journal of Hebei University of Engineering (Social Science Edition), vol. 30, no. 3, pp. 127-129, 2013.

[6] P. L. Yang, S. S. Liu, Y. Gao, "Student Information Management System Design and Implementation Based on ADO.NET," Computer Technology and Development, vol. 20, no. 5, pp. 238-241, 2010.

[7] C. Y. Zhu, M. N. Chen, C. Ni, K. Fang, "Design of Network Management System for Physics Experimental Teaching," Experimental Technology and Management, vol. 25, no. 1, pp. 98-100, 2008. 